\title{
The effect of the Qinghai-Tibet railway on the migration of Tibetan antelope Pantholops hodgsonif in Hoh-xil National Nature Reserve, China
}

\author{
Lin Xia, Qisen Yang, Zengchao Li, Yonghua Wu and Zuojian Feng
}

\begin{abstract}
The Tibetan antelope or chiru Pantholops hodgsonii is endemic to the Tibetan plateau and was once abundant over vast areas of high elevation grassland habitat. During the 20th century, however, the population declined greatly in numbers. Hunting used to be the main threat to this species but recent actions by the government and wildlife protection organizations have brought this under control. With the development of north-west China, conflicts between development of transportation facilities and conservation have become more acute, and heavy traffic on the Golmud-Lhasa highway and the construction of the Qinghai-Tibet railway across key migration corridors have disturbed the migration of Tibetan antelopes. During June to August 2003 and 2004 we monitored the movement of Tibetan antelopes across the railway and highway and recorded
\end{abstract}

their passes at wildlife crossing structures, which was the first use of such structures in China. Our results show that the efficiency of passages greatly improved between 2003 and 2004, and that use of wildlife corridors was affected by the structure of the passage, presence of wolves, recovery of vegetation following damage during construction, and other factors. The disturbance to migration of Tibetan antelopes included infrastructure, human activities, road traffic, construction of the railway and so on. The impact of infrastructure, especially transportation development, on the habitat and migration of Tibetan antelopes are the main factors that threaten this species now and in the future.

Keywords Chiru, migration, Pantholops hodgsonii, Tibetan antelope, traffic disturbance, wildlife passages.

\section{Introduction}

The Tibetan antelope or chiru Pantholops hodgsonii, endemic to the Tibetan plateau, is categorized as Endangered on the IUCN Red List (IUCN, 2006) and listed on Appendix I of CITES (CITES, 2000). In China it is a Class I protected species (State Forestry Administration of China, 1998). The distribution of the Tibetan antelope extends from Ngoring $\mathrm{Hu}$ in China and the Ladakh region in India in the west to Ganzi of Sichuan Province in the east, and from the Himalayas in the south to the Kunlun and Altun mountains of Xinjiang in the north (Wu \& Feng, 1996; Schaller et al., 1998). Most of the species' range lies at $>4,000 \mathrm{~m}$ altitude, although in parts of Xinjiang the species formerly occurred as low as $3,250 \mathrm{~m}$. The chiru prefers flat to rolling topography and alpine steppe or similar semi-arid plant associations, and although its distribution was probably continuous in the past it is now fragmented (Schaller, 1998).

There are no accurate historical estimates of chiru numbers (Schaller, 1998), although a few early explorers

Lin Xia, Qisen Yang (Corresponding author), Zengchao Li, Yonghua Wu and Zuojian Feng Institute of Zoology, Chinese Academy of Sciences, Beijing, 100080, China. E-mail yangqs@ioz.ac.cn

Received 28 January 2005. Revision requested 8 August 2005. Accepted 19 September 2005. made some observations (Bonvalot, 1892; Wellby, 1898; Deasy, 1901). Schaller (1998) estimated an historical population of $500,000-1,000,000$ based on the limited information available. In the past 30 years the population is believed to have declined rapidly, mainly because of poaching for shahtoosh, and the total population in the mid 1990s may have been as low as 65,000-75,000 (Schaller, 1998).

Seasonal migration is one of the main characteristics of chiru ecology and reproduction. Each summer adult females and their female offspring of the previous year travel c. $300 \mathrm{~km}$ from their winter mating grounds to summer calving grounds. Males tend to remain near the wintering grounds. In late June to July single calves are born. Formerly there were at least four, and possibly more, major migratory populations on the Tibetan plateau (Schaller, 1998). The grasslands surrounding Zhuonai and Taiyang lakes, in the north-west of Hoh-xil National Nature Reserve, have been identified as major current calving grounds of Tibetan antelopes (Feng, 1991), and females of the population discussed here migrate from Sanjiangyuan to Hoh-xil each summer, and return each autumn.

This population was formerly subjected to poaching but is now one of the best protected chiru populations. However, the newly built Qinghai-Tibet railway and the existing highway both cut across the population's 
migration corridor at the boundary between Hoh-xil National and Sanjiangyuan Nature Reserves (Xia \& Yang, 2004a,b,c), 130-150 km from the calving grounds. The highway (the Xining-Lhasa section of the National Trunk Highway no. 109) begins in Xining, Qinghai Province, in the north and ends in Lhasa in Tibet. Construction began in 1950 and it was opened in December 1954. It crosses the Kunlun mountain, Hoh Xil and Tanggula mountains and the Zangbei plateau, with a total length of $1,900 \mathrm{~km}$; the road is $10 \mathrm{~m}$ wide. The highway is the most important transportation lifeline to the Tibetan plateau, carrying nearly $85 \%$ of Tibet's inbound and outbound goods. Construction of the Golmud to Lhasa section of the Qinghai-Tibet railway began in June 2001; it is built along the Golmud river, goes across the Kunlun mountain, through Hoh Xil and Fenghuo mountain, across Tuotuo river and into Tangula mountain, passes along the Damxiong and Yangbajing valley, and ends in Lhasa, Tibet. To ensure that Tibetan antelopes and other species could cross the railway, 15 animal passages were built in the area of their migratory route but no corridors have been built across the highway (Yang et al., 2003).

Little is known about the disturbance of Tibetan antelope by road traffic (but see Qiu \& Feng, 2004) and there is almost no information and experience concerning the use of passages. Here we report on the monitoring of the impacts of transportation infrastructures on this migratory herd of Tibetan antelope and suggest some mitigation measures for these impacts.

\section{Study area}

The Hoh-xil National Nature Reserve, Qinghai Province, has an average altitude of 4,500 $\mathrm{m}$ (Liu \& Yin, 1993). The topography consists of rolling hills and shallow gullies, and the habitat is high altitude steppe, alpine meadow and gravel-filled gullies, entirely without trees or shrubs. Fieldwork was conducted from Chumaer river to North Wudaoliang, along the newly built Qinghai-Tibet railway and the parallel highway on the boundary of Hoh-xil and Shanjianguyan National Nature Reserves (Fig. 1). The monitoring area was a $10 \mathrm{~km}$ width of the migration route that included the following crossing structures:

(1) Underpass at Chumaer River Bridge. This location used to be the most important part of the migration route in this area. The main structure was finished in 2003 and put into use in 2004 but the land surface under the bridge was destroyed by construction machinery and not cleared. Although the construction was halted during the chiru migration, the workers remained at the site. (2) Overpass at Chubei Bridge. This is $2 \mathrm{~km}$ north-west of Chumaer River Bridge. The construction was unfinished at the time of this study, and human activities continued. (3) Underpass at Wubei Bridge. This has become the main route for Tibetan antelope migration in this area. The main construction was completed in June 2004 and most of the workers departed, together with most of the machinery, but there is still some machinery and debris under the bridge. (4) Wudaoliang Railroad Bridge. This was not designed for passage by Tibetan antelopes but could be used by them as an underpass. There is a large open area near the passage, a construction site nearby, and part of the structure was still being built during this study. (5) Other small bridges and culverts. Most of these are 1-2 $\mathrm{m}$ in height and 5-10m long. They are dark, narrow corridors, and the land surface under the bridges has not been cleared of debris or restored.

\section{Methods}

Over 15 June-31 August 2004 we used video cameras, counts and observation to monitor the movement of the migrating herd of Tibetan antelopes along the highway and railway. Video cameras were used in two underpasses (Chumaer River Bridge and Wubei Bridge) to record the passage of antelopes. The cameras can work for 8-10 hours continuously, with a solar power supply during the daytime. Four video cameras were mounted under each of the two bridges, i.e. 8 in total, and recording was with a time lapse video recorder.

During the observation period $56 \%$ of the days were cloudy, and snow and rain occurred on $28 \%$ of the days, limiting video recording. At such times we therefore made direct counts of the number of passing chiru, including group sizes, with a 15-45x telescope in the daytime (chiru rest at night). A group was defined as all individuals within $50 \mathrm{~m}$ of each other. Yearlings and adults are difficult to differentiate at a distance, and only composition of those herds for which determinations are judged to be reliable were included in subsequent analysis of herd composition.

In the area of the crossing structures we also carried out daily monitoring, by vehicle, for any chiru that crossed the highway or crossed directly over the railway without using any crossing structures. In addition we recorded human activities brought by the highway, traffic flow on the highway, and crossings by chiru from 09.00 to 20.00 during 6 peak days of the western migration.

\section{Results}

From 21 June to 2 July 2004 1,660 chiru were counted at Wubei Bridge as they moved westward from their wintering range in Sanjiangyuan National Nature Reserve to their calving grounds in Hoh-xil National 


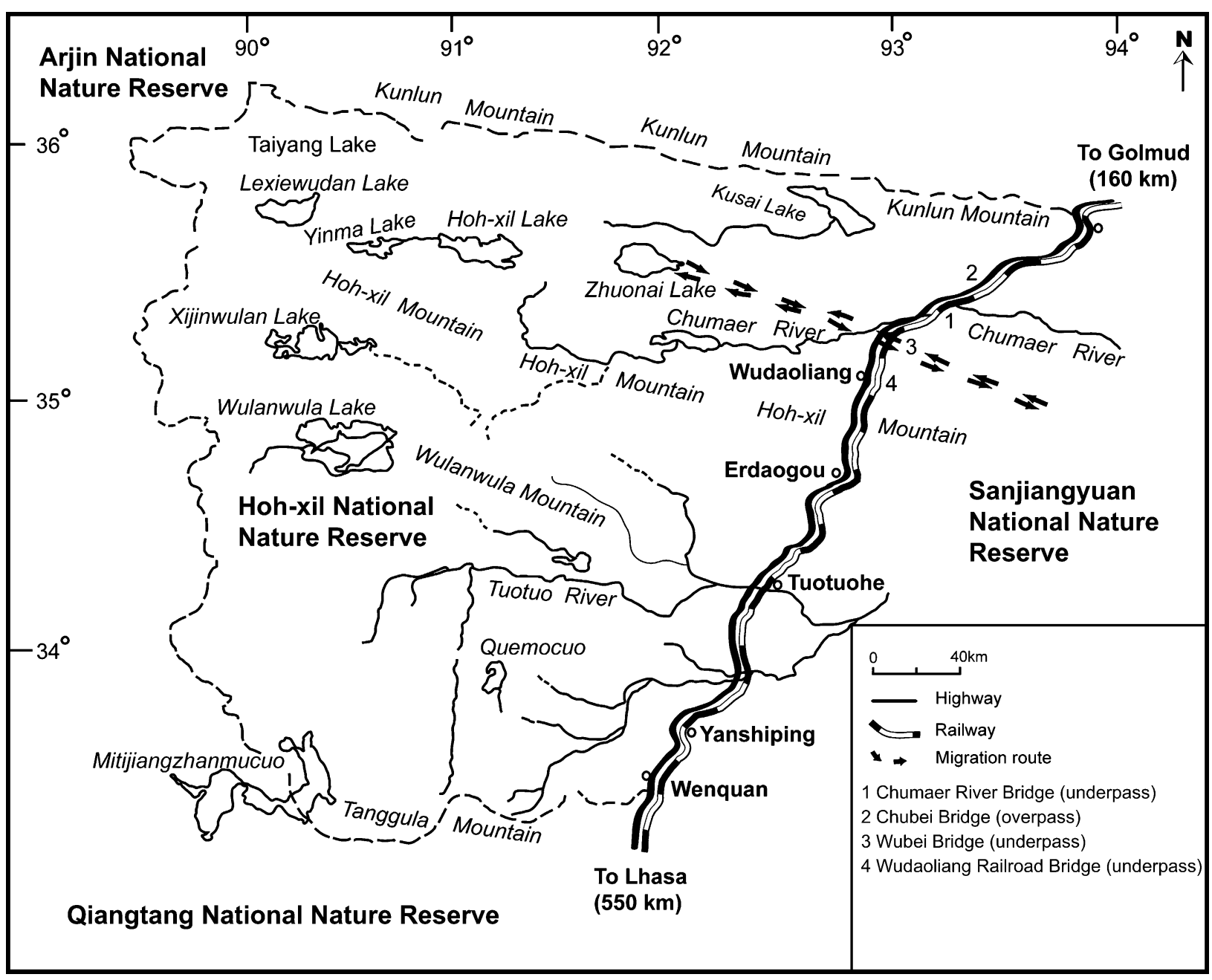

Fig. 1 The study area in the Hoh-xil National Nature Reserve, indicating the location of the chiru migration route and the railway crossing structures (see text for further details).

Nature Reserve, including adult and subadult females and nine newborn (Table 1), and all used the underpass. The construction of the railway near the underpass was halted during the migration. Chiru had a tendency to form large herds in the underpass. We recorded 29 groups, with an average size of $256.9 ; 67.4 \%$ of individuals formed groups $>300$ (Fig. 2). None of the other passage structures were used by the chiru during this period.

In late July antelopes returned with their newborn from the calving grounds to their winter range. In 51 groups sampled randomly, we recorded 1,008 newborn and 1,894 adult and subadult females, i.e. a ratio of young to females of 53:100. These groups were smaller in size (Fig. 2), but individuals were more dispersed than in the westward migration; no groups had $>350$ individuals, and average group size was 87.7. Construction was suspended for the migration from 8 August, but after 18 August construction near the underpass at Wubei Bridge resumed and no individual chiru were recorded using underpasses after this date. From 8 to 29 August a total of 2,303 individuals were recorded crossing the railway. Compared to the westward migration, however, a lower percentage of the antelopes used the underpass at Wubei Bridge, a few used the underpass at Chumaer River Bridge, and two passed through a culvert (Table 1). In addition to the 1,291 chiru counted using these crossing structures, 1,202 (44\% of the total) were counted crossing the rail bed directly, 517 during the period when construction was suspended and 495 during the construction period.

The railway is a physical barrier and its impact on the activity of chiru was visibly apparent. When antelopes reached the railway they hesitated under the slope of the rail bed and gathered into large groups. The modification of the land surface in the underpasses and along the railway appeared to have a major effect. For example, one afternoon we saw a small group of chiru, which had just crossed the highway, running along the railway. They reached a small bridge $10 \mathrm{~m}$ long and $2 \mathrm{~m}$ high and 
Table 1 The number of chiru using the various crossing structures (Fig. 1) along a $10 \mathrm{~km}$ stretch of the railway during the westward $(21 / 6-2 / 7)$ and eastward (8/8-29/8) migrations, and the types of disturbance at each structure.

\begin{tabular}{|c|c|c|c|c|}
\hline \multirow[b]{2}{*}{ Structure } & \multirow[b]{2}{*}{ Type } & \multicolumn{2}{|c|}{ No. of individuals ( $\%$ of total) } & \multirow[b]{2}{*}{ Disturbance } \\
\hline & & Westward & Eastward & \\
\hline $\begin{array}{l}\text { Chumaer } \\
\text { River Bridge }\end{array}$ & Underpass & 0 & $41(1.8)$ & $\begin{array}{l}\text { Uncleared construction material, equipment \& vehicles; human } \\
\text { activities; short distance between highway and crossing } \\
\text { structure }\end{array}$ \\
\hline Chubei Passage & Overpass & 0 & 0 & $\begin{array}{l}\text { Uncleared construction material, equipment \& vehicles; } \\
\text { human activities }\end{array}$ \\
\hline Wubei Bridge & Underpass & $1,660(100)$ & $1,248(54.2)$ & Uncleared construction material; human activities \\
\hline $\begin{array}{l}\text { Wudaoliang } \\
\text { Railroad Bridge }\end{array}$ & Underpass & 0 & 0 & $\begin{array}{l}\text { Main construction site; large amount of construction materials } \\
\& \text { workers; land surface destroyed; railway accessories; } \\
\text { human activities }\end{array}$ \\
\hline Other small bridges & Underpass & 0 & $2(0.1)$ & The structure itself; environment not restored; human activities \\
\hline Culverts & Underpass & 0 & 0 & The structure itself \\
\hline Total & & 1,660 & 1,291 & \\
\hline
\end{tabular}

made some attempts to cross under it; one adult passed through it successfully but on the other side she stopped by a piece of railway track debris and turned back. This also happened sometimes when a small hole, bricks, or tools used in construction were left in an underpass. The antelopes seemed wary of anything on the land surface of the underpasses, although they sometimes ignored the train running over the railway above.

Average traffic flow recorded on the highway during 6 days was 1.2 vehicles per minute, with a maximum at 13.00-14.00 (Fig. 3) when flow reached 3.3 vehicles per minute. There was a high frequency of crossings by chiru during the most busy period of traffic (Fig. 3).

\section{Discussion}

Within the $10 \mathrm{~km}$ of railway studied all chiru passed through the crossing structures on their westward migration and $56 \%$ used the crossing structures on the return eastward migration. Therefore, although the railway structure itself does have significant impacts on the behaviour of chiru during migration, it does not disrupt the migration corridor. According to railway construction planners and the Qinghai Environmental Protection Bureau the area affected by the rail bed's construction is to be returned to its original condition, and we saw some turf being transplanted back to the rail bed. In general the swathe of tundra disrupted by railway construction is narrow but the most disturbed areas are the staging areas and sand quarries located off to the side of the railway. As the main structure of the railway is finished the condition of passage for chiru will improve. However, where construction debris still occurs under the crossing structures or along the railway, the use of passages by antelope is affected. Once the railway construction firms have removed all equipment and restored the vegetation we believe that the efficiency of crossing structures will be improved.

The railway does not appear to be disturbing the birth rate of chiru. During 1990-1993 the ratio of young to females ranged from 30:100 to 50:100 during AugustOctober in Qiangtang (Schaller, 1998), another part of the

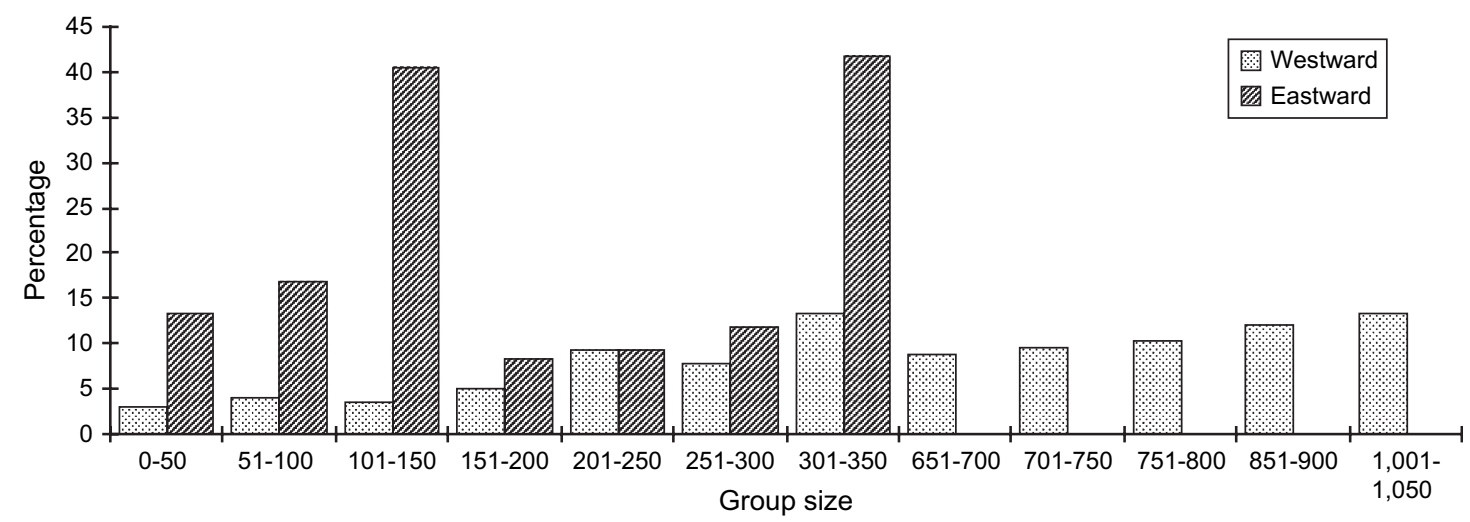

Fig. 2 Percentage of total monitored chiru in different group sizes during the westward (21/6-2/7) and eastward (8/8-29/8) migrations. 


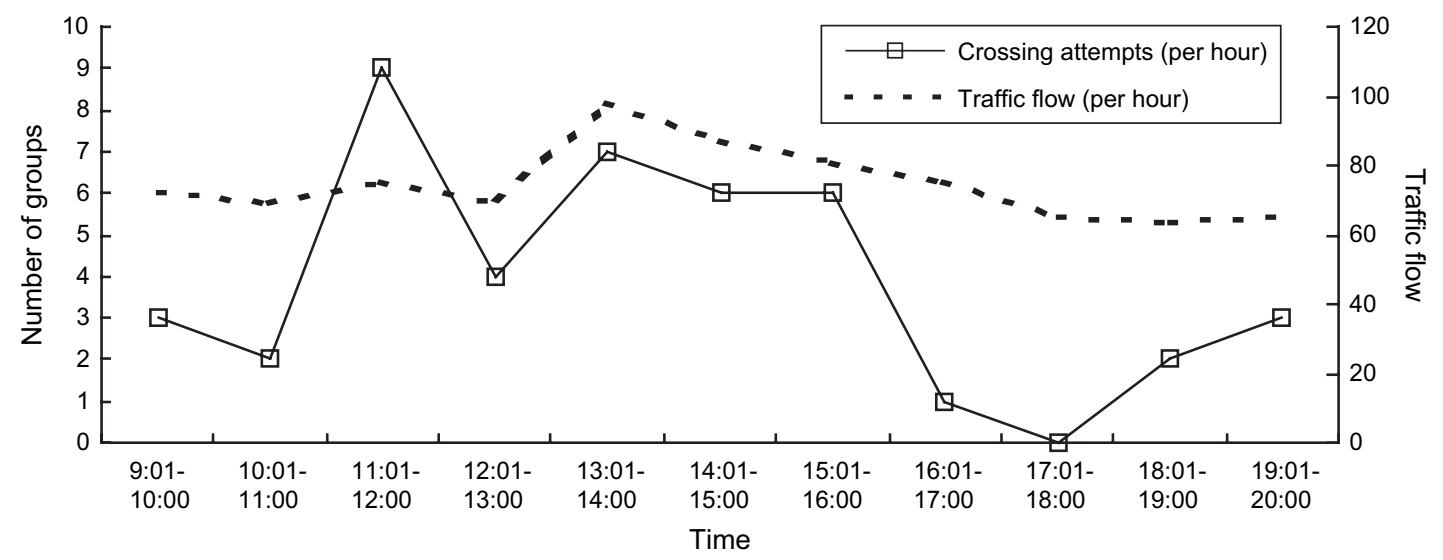

Fig. 3 Traffic flow on the highway and crossing attempts made by chiru, recorded during 6 peak days of the western migration.

winter range of chiru. We recorded a slightly higher ratio, of 53:100, but mortality of calves can be expected to continue during the migration. We expect the final ratio of young to adult females will drop to 30:100 - 40:100 by the autumn as Schaller (1998) noted that one third of the young died during the winter and early spring.

On the return, eastward migration, the chiru first meet the highway, and if they fail to cross it they will not then cross the railway. Of the four highways on the Tibetan plateau the condition of the Golmud-Lhasa highway is the best. In the rainy season buses, trucks and other vehicles select this route because of safety considerations. Use of the railway will probably change this situation for the better, reducing traffic flow. By 2007, 16 trains will travel between Golmud and Lhasa every day, and the pressure of road traffic may be reduced.

Human activities, including the activities of tourists, railway construction workers and other persons brought by highway, were the most serious factor that affected the efficiency of all crossing structures. Chiru are active in the daytime and therefore cannot avoid the disturbance of human activities. The migration season is in summer, which was the busiest period for construction of the railway and other activities on the plateau. We observed that activities along the highway such as chasing, shouting, and taking pictures scattered the chiru herd, making it difficult for them to cross. Although during the short periods of the westward and eastward migrations all construction activities were limited near the main wildlife passages, the activities of tourists and truck drivers were not controlled. Increasing human presence associated with railways and highways may be the main threat to this species now and in the future, and may be greater than the threat from the infrastructures per se.

Based on our monitoring and the evaluation of the crossing structures, we make the following recommen- dations: (1) Continue to halt or limit human activities near wildlife passages in future migration seasons. The activities of tourists, researchers and truck drivers should also be limited by the managers of the neighbouring reserves. (2) Ensure that the Transportation Department removes all equipment and restores the vegetation at all construction and repair sites. (3) The highway will be refurbished by 2009. The refurbishment should include the construction of passages to reduce the negative effects of the road as currently there are no crossing structures on the highway. (4) The railway is at the boundaries of the Hoh-xil and Sanjiangyuan National Nature Reserves but the railway and highway are managed by the Transportation Department. The chiru moves across land managed by all three bodies, however, and there needs to be improved cooperation between the the two reserves and the Transportation Department to reduce disturbance to the migration of the chiru. (5) We found that the local people living in the vicinity of the migration route and people who travel by the road lack general knowledge about the chiru and of wildlife conservation in general. More efforts should be made to strengthen the education of the public, with programmes designed for people with different educational backgrounds, drivers on the highway, and workers on the highway during the forthcoming refurbishment. Efforts are needed not only to improve public awareness of Tibetan antelope conservation and to counter any potential poaching, but also to increase general knowledge of conservation and the importance of the wildlife passages. (6) Further research on the effects of both the railway and road on the migration of chiru are required, including long-term monitoring of the migration. In any future transportation developments in this region the government and Transportation Department will require information to make appropriate conservation plans for any periods of construction. 
Our monitoring results and recommendations were passed to the Bureau of Forestry (which manages Sanjiangyuan Nature Reserve), the Transportation Department, and the administration of Hoh-xil National Nature Reserve. The information was used by both the local government and transportation agencies to make conservation plans for the migration season of 2007. Monitoring of migration and evaluation of the wildlife corridors will continue to be supported by the Ministry of Railways. Further research is planned to assess the disturbance to mammals along the railway and the highway up to 2008 .

\section{Acknowledgements}

This study received financial support from the BP Conservation Programme and the Chinese Ministry of Railways. We express our gratitude to Fauna \& Flora International, the Wildlife Conservation Society, Conservation International, and BirdLife International. We also thank William Bleisch and an anonymous reviewer for help in revising the manuscript and for other useful advice.

\section{References}

Bonvalot, G. (1892) Across Tibet. Cassell, New York, USA. CITES (2000) Conservation of and Control of Trade in Tibetan Antelope. Http://www.cites.org/eng/res/11/11-08R13.shtml [accessed 8 November 2005].

Deasy, H. (1901) In Tibet and Chinese Turkestan. Green, NewYork, USA.

Feng, Z.J. (1991) Wild animal resources in the Hoh Xil region. Chinese Journal of Arid Land Resources, 4, 247-253.

IUCN (2006) 2006 IUCN Red List of Threatened Species. IUCN, Gland, Switzerland [http://www.redlist.org, accessed 28 December 2006].

Liu, W.L. \& Yin, B.G. (eds) (1993) Precious and Rare Wildife and its Protection in Tibet. China Forestry Publishing House, Beijing, China. [in Chinese]

Qiu, L. \& Feng, Z.J. (2004) Effects of traffic during daytime and other human activities on the migration of Tibetan antelope along the Qinghai Tibet highway, Qinghai Tibet Plateau. Acta Zoologica Sinica, 50, 669-674.

Schaller, G.B. (1998) Wildlife of the Tibetan Steppe. Wildlife Conservation Society \& Tibetan Plateau Project, University of Chicago, Chicago, USA.

State Forestry Administration of China (1998) Conservation Status of the Tibet Antelope. Translated by WWF, China. China Forestry Publishing House, Beijing, China.

Wellby (1898) Through Unknown Tibet. London, UK.

$\mathrm{Wu}$, S. \& Feng, Z.J. (1996) The Biology and Human Physiology in the Hoh Xil Region. Sciences Press, Beijing, China.

Xia, L. \& Yang, Q.S. (2004a) Wildlife conservation along Qinghai-Tibet Railway. Discovery of Nature, 4, 29-31.

Xia, L. \& Yang, Q.S. (2004b) Wildlife passages. Discovery of Nature, 4, 26-28.

Xia, L. \& Yang, Q.S. (2004c) Wildlife crossing structures and conservation of Tibetan antelopes. China Nature, 2, 6-8.

Yang, Q.S., Xia, L., Lei, F.M. \& Feng, Z.J. (2003) Present situation of wild animal resources along Qinghai-Tibet railway line and countermeasures of protection. Journal of Shenyang Normal University, 21, 69-77.

\section{Biographical sketches}

Lin Xia has taken part in various biodiversity and conservation research projects on the mammals of north-west China, participated in the design of the animal crossing structures for the Qinghai-Xizang railway, and is currently working on the conservation of musk deer and Tibetan antelope.

Qisen Yang carries out research on mammalian taxonomy and the conservation of wildlife of the Qinghai-Xizang (Tibet) Plateau, and was one of the main designers of the animal crossing structures on the Qinghai-Xizang railway.

Li Zengchao is experienced in biodiversity conservation and field surveying techniques.

Yonghua $\mathrm{Wu}^{\prime}$ s research interest is the conservation biology of large mammals.

Zuojian Feng is Vice Secretary General of the China Zoological Society, has considerable experience in conservation and field surveys of threatened animals in Tibet, over 40 years experience carrying out research in Qinghai and Xizang, and also participated in the design of the animal crossing structures for the Qinghai-Xizang railway. 